IMAFRONTE-No 27.2020 , pp. 1-16

ISSN: 0213-392X / eISSN: 1989-4562

DOI: https://doi.org/10.6018/imafronte.460351

\title{
EN TORNO AL TEMPLO PARROQUIAL DE NUESTRA SEÑORA DE LA ASUNCIÓN DE CIEZA (SIGLOS XVIII-XIX) ${ }^{1}$
}

\author{
AROUND THE PARISH TEMPLE OF NUESTRA SEÑORA DE LA ASUNCIÓN \\ DE CIEZA (XVIII-XIX CENTURIES)
}

\author{
MANUEL MARÍN RODRÍGUEZ
}

Recibido: 11/05/2020 / Aprobado: 30-07-20

\section{RESUMEN}

En este artículo se realiza un estudio histórico-artístico sobre la Basílica de Nuestra Señora de la Asunción de Cieza, desde sus orígenes hasta el final de su construcción en 1873, dando a conocer los diversos canteros y arquitectos que intervinieron en el proceso de sus obras, periodo que, según se desprende de la bibliografía y la documentación consultada, parece ser que abarcó desde finales del siglo XVII hasta finales del siglo XIX, momento en el que se concluye su torre campanario por parte del arquitecto murciano José Marín Baldo, cuyo proyecto original redactado en 1873, queda plasmado en el apéndice documental que lo acompaña.

PALABRAS CLAVE: Toribio Martínez de la Vega, Salvador de Mora, José Marín Baldo, Torre Campanario, Templo Parroquial, Cieza (Murcia).

\section{ABSTRACT}

In this article a historical-artistic study is carried out on the Basilica of Our Lady of the Assumption of Cieza, from

\footnotetext{
${ }^{1}$ Quiero aprovechar este espacio para agradecer las recomendaciones y sugerencias aportadas por la profesora María Teresa Marín Torres durante la elaboración del presente artículo, así como también agradezco la ayuda y el apoyo recibido por la profesora Concepción de la Peña Velasco, y María del Carmen Sánchez-Rojas, quién además me facilitó la transcripción de algunos documentos históricos relacionados con la intervención del arquitecto Toribio Martínez de la Vega en este Templo Parroquial de la Asunción de Cieza, documentos que me hicieron conocer en mayor profundidad la historia de la construcción de esta grandiosa obra del patrimonio monumental de Cieza.

También quisiera agradecer la ayuda de D. Joaquín Salmerón Juan, Director del Servicio de Patrimonio Histórico del Ayuntamiento de Cieza, por haberme facilitado buena parte de las fuentes bibliográficas más antiguas sobre la historia de Cieza, que en este caso me han sido muy útiles a la hora de abordar los apartados de este artículo que hacen referencia al origen del templo parroquial de la Asunción.
} 
its origins until the end of its construction in 1873, making known the various stonecutters and architects who intervened in the process of their works, a period that, as can be seen from the bibliography and the documentation consulted, seems to have spanned from the end of the 17th century until the end of the 19th century, at which time its bell tower is completed by the Murcian architect José Marín Baldo, whose project original written in 1873, is reflected in the accompanying documentary appendix.

KEY WORDS: Toribio Martínez de la Vega, Salvador de Mora, José Marín Baldo, Bell Tower, Parish Church/ Cieza (Murcia).

\section{INTRODUCCIÓN}

El templo parroquial de Nuestra Señora de la Asunción es el edificio más relevante del patrimonio monumental de Cieza (Amador de los Rios, 1889), se encuentra ubicado en la Plaza Mayor, lugar que desde el punto de vista urbano, se convierte en el eje central del casco antiguo de Cieza. Este templo fue construido entre los siglos XVII y XIX, aunque sus obras adquirieron su mayor esplendor en el siglo XVIII, momento en el que se van a remodelar buena parte de los edificios religiosos que habían sido erigidos durante siglos anteriores (Hernández y Segado, 1984), así como también se procede a edificar diversos monumentos religiosos, tales como iglesias y conventos (Rivas, 2007), casi todos ellos impulsados por el Obispo Belluga (Hernández, 2006), quien durante estos momentos se convirtió en el promotor de todas las edificaciones religiosas del antiguo Reino de Murcia (Vera, 1990), al que Cieza también perteneció.

El siglo XVIII no fue solamente un tiempo de esplendor en el ámbito eclesiástico, puesto que en estos momentos, la nobleza también adquirió un papel importante en el desarrollo urbano de la ciudad (Hernández 2016; Calvo, 2011), estamento social que además de financiar diversas obras religiosas, mandó construir sus propias edificaciones, mayoritariamente palacios y casas solariegas blasonadas en las que a través de la decoración artística de sus fachadas, quedó reflejado el alto poder adquisitivo que dicho estamento social tuvo en aquellos momentos. Desde el punto de vista urbano (Bonet, 1991; De la Peña, 1992), los edificios civiles y religiosos levantados durante el siglo XVIII (De la Peña, y Hernández 1994), se convirtieron en el símbolo más importante de la ciudad, situación que también tuvo lugar en antigua villa de Cieza, aunque quizá, en menor medida en relación con lo sucedido en la ciudad de Murcia (Gutiérrez-Cortines y Hernández, 1983), donde la portada principal de la Catedral, situada en la Plaza de Belluga, y ejecutada por Jaime Bort hacia 1750 (Hernández, 1990; Gutiérrez-Cortines, 1990), se convirtió en una de las obras monumentales más importantes del periodo Barroco (Gutiérrez-Cortines, 1990).

El templo parroquial de la Asunción no fue el único edificio religioso construido en Cieza, pues a escasos de metros del mismo, y emplazada junto al Balcón del Muro, uno de los puntos turísticos más estratégicos de la ciudad, se encuentra la ermita de San 
Bartolomé, un edificio del siglo XVIII de planta centralizada y de doble altura que parece ser que fue erigido prácticamente de forma paralela al templo de la Asunción, en cuyo interior habita la imagen escultórica del patrón de Cieza, San Bartolomé. Además, en Cieza, junto a los edificios mencionados, conviven otros no menos importantes con respecto a los anteriores en cuanto a sus valores histórico-artísticos, tales como el convento franciscano de San Joaquín y San Pascual, edificio desamortizado en el siglo XIX, a excepción de su iglesia, cuya tipología arquitectónica responde a los modelos establecidos por la Orden Jesuita en el templo de Il Gesú de Roma (Rodríguez, 2002).

El monasterio de la Inmaculada Concepción (De la Rosa, 1992), costeado por la familia Marín-Blázquez hacia 1750, y la ermita del Santo Cristo del Consuelo, ejecutada por los arquitectos murcianos Juan José Belmonte y Almela (1808-1875) y Justo Millán Espinosa (1843-1928) durante el siglo XIX, junto a las edificaciones que se han mencionado anteriormente, conforman en la actualidad el patrimonio religioso monumental de la ciudad.

Los retablos y buena parte de las imágenes de culto que se localizaban en el interior de estos edificios religiosos, fueron destruidas durante el trágico episodio de la Guerra Civil Española (1936-1939), y fueron sustituidas por otras esculturas más modernas elaboradas por artistas murcianos de la posguerra, de entre los que cabe destacar a Juan González Moreno (1908-1996), quién recibió múltiples encargos por parte de diversas cofradías y hermandades de la Semana Santa de Cieza para recuperar su patrimonio artístico desaparecido (Carrasco, 2005).

\section{ALGUNOS DATOS SOBRE EL PRIMITIVO TEMPLO}

El actual templo parroquial de la Asunción fue construido sobre los restos de una antigua iglesia dedicada a la advocación de Santa María. Un templo de reducidas dimensiones levantado hacia 1492, probablemente la única iglesia que había por aquel entonces en la villa de Cieza, a pesar de que en la Relación Topográfica de Felipe II del año 1579 , se hace alusión a la existencia de otra iglesia vieja previamente abandonada (Capdevila, 1928).

Este primitivo templo dedicado a la advocación de Santa María, que en un primer momento se caracterizaba por sus reducidas dimensiones, parece ser que a lo largo del tiempo sería sometido a diversas ampliaciones, puesto que en el año 1520 se solicitó permiso al monarca Carlos I para proceder a su ampliación, obteniéndose como resultado de la misma, el cambio de disposición de la nave central, quedando la nave central a partir de aquel momento en sentido perpendicular con respecto a su orientación primigenia (Carrasco, 2004; González, 1997).

Las noticias del primitivo templo sobre el que fuera construida la actual iglesia de la Asunción son bastante escasas, pero sin embargo, un estudio documental más exhaustivo realizado posteriormente sobre la antigua parroquial de Santa María revela que:

...el pequeño templo se estructuró por medio de una reducida cabecera que sería ampliada a partir de las citadas obras, un cuerpo central compuesto presumiblemente de tres naves separadas por columnas 
y dos capillas en los laterales; asimismo, se desconocen las dimensiones de un supuesto crucero, lo que incide en la hipótesis abierta de una planta cruciforme o bien cercana a la tipología basilical. Además la iglesia contaba con dos puertas de acceso, la menor y la principal; y junto a ésta, se ubicó desde mediados del siglo XVII la entrada al coro. Igualmente, se desconoce dónde se ubicaban, más aceptando su disposición longitudinal, la principal quedaría en su lateral occidental, a la altura de un supuesto crucero (Marín, 2008: 43).

En esta investigación también se pone de manifiesto que el antiguo templo de Santa María fue concebido como la morada última de algunos ciezanos, pudiéndose distinguir a finales del siglo XVI tres enterramientos abiertos y cuatro cerrados. En la Relación Topográfica de Felipe II, se establece que hubo dos tipologías de enterramientos (Marín, 2008), por una parte aquellos que giraban en torno a un espacio cerrado a modo de capilla, y por otra parte, otros que tenían sepulturas en sus espacios comunes con el templo, imposibilitando que pudieran estar acotados. De todos los enterramientos que hubo en la antigua iglesia de Santa María, destacaron aquellos que pertenecieron a los herederos de doña Urraca (Marín, 2008), quienes parece ser que hicieron donaciones para la construcción de la capilla mayor, motivo por el que probablemente, sus enterramientos quedaron localizados en el centro del ábside de la misma.

\section{LAS OBRAS DEL NUEVO TEMPLO DE LA ASUNCIÓN}

El aumento del número de población que la villa de Cieza iba llevando consigo conforme al paso de los años, y el estado ruinoso que la antigua iglesia de Santa María presentaba, motivó que en el año 1694 se procediera al derribo de la nave central de este antiguo templo, salvo la cabecera, que se había empezado a construir hacia 1614 por el arquitecto Diego de Villabona, pasando la obra un año después en 1615 a manos del arquitecto francés Agustín Bernardino (Carrasco, 2004). No obstante, parece ser que el diseño y las trazas de la capilla mayor se debieron al maestro Juan de Sitién, siendo Diego de Villabona y posteriormente Agustín Bernardino, quienes siguiendo el diseño y las trazas enviadas por Juan de Sitién, probablemente construirían entre 1614 y 1615 la capilla mayor de la iglesia parroquial de la Asunción (Marín, 2004).

Diego de Villabona y Agustín Bernardino, en estos momentos constituían los ejemplos más destacados del panorama arquitectónico murciano, puesto que Diego de Villabona había trabajado anteriormente a las obras de la Asunción de Cieza, en la Colegiata de San Patricio de Lorca (Segado, 2007 y 2012) y en la iglesia de Santiago de Orihuela, mientras que Agustín Bernardino trabajó tanto para la iglesia de Santa María de Alicante como para el Colegio de Santo Domingo de Orihuela (Sánchez, 1985; Penalva, 2017), así como también parece ser que intervino en las obras del Santuario de la Vera Cruz de Caravaca, templo considerado prácticamente contemporáneo al de Nuestra Señora de la Asunción de Cieza (Hernández y Segado, 1980).

Una vez que el cuerpo principal de la antigua iglesia parroquial es derribado, hacia 1695 se empezó a levantar el nuevo templo de la Asunción, cuyas obras fueron ejecutadas por el arquitecto Lucas de la Lastra (Marín, 2008). No obstante, su aportación en las obras de la parroquial de la Asunción fueron poco conocidas aunque parece ser que este arquitecto pudo ocuparse de las obras de la parroquial de Blanca a la muerte de su hermano en 1996, compaginando estas con las obras de la torre de la iglesia de Santiago 
de Jumilla (Marín, 2004), mientras que su intervención en la parroquia de Cieza no sería hasta la primera década del siglo XVIII.

Los gastos de las intervenciones realizadas durante el siglo XVIII fueron sufragados por la Encomienda de la villa de Cieza, el Cabildo Catedralicio, el Obispado y por el Concejo de Cieza, comprometiéndose la Encomienda de la villa a pagar 24.000 reales, el Cabildo y el Obispado 10.000 reales y el Concejo el resto del presupuesto restante hasta llegar a los 45.000 reales de vellón que Lucas de la Lastra había presupuestado (Carrasco, 2004).

En las obras de la iglesia de la Asunción durante el siglo XVIII, también trabajó el arquitecto Toribio Martínez de la Vega (Sánchez-Rojas, 1987), nombrado en 1703 tasador de sus materiales por el Cabildo de la Catedral de Murcia:

...Licencia que pone al servicio de necesitar por Canonico que Expresa de que Toribio Martinez Maestro de Alarife y Canteria pase â el reconocimiento Y tasazion de la Iglesia Parroquial de la Villa de Cieza... ${ }^{2}$

Toribio Martínez de la Vega fue conocido en el siglo XVIII por sus trabajos tanto en arquitectura religiosa como hidráulica en el antiguo Reino de Murcia, por lo que destaca su intervención en la Colegiata de San Patricio de Lorca, la Catedral de Murcia, la reforma del Puente Barraumal de Alcantarilla y la construcción del Puente Viejo de Murcia. Martínez de la Vega tenía una excelente formación como arquitecto, de modo que siempre trataba de conseguir el máximo rendimiento en la ejecución de sus obras, adaptando sus diseños a las condiciones específicas de cada lugar, corrigiendo diversos aspectos de las trazas y adoptando las soluciones adecuadas en cada momento, con el objetivo de lograr la máxima perfección en la elaboración de cada uno de sus proyectos (De la Peña, 2001; Espín, 1986).

Durante el siglo XVIII, la estructura arquitectónica de la iglesia quedaría configurada tal y como la conocemos en la actualidad, se trata de una iglesia que a pesar de estar construida en estilo Barroco, sin embargo, desde su exterior se dejan ver ciertas reminiscencias del estilo renacentista (Gutiérrez-Cortines, 1987), algo que en concreto queda patente en sus dos portadas laterales, una de ellas dedicada a la advocación de San Pedro y otra a la de Santa María, ambas constituidas por un arco de medio punto a modo de arco de triunfo romano y dos pilastras adosadas en orden gigante a ambos lados, que a modo de decoración, sin ninguna función estructural, soportan en la parte superior un friso de tradición clásica, y un frontón triangular quebrado.

La iglesia de la Asunción está constituida por una planta basilical de tres naves con capillas laterales, cabecera de testero plano y coro a los pies, donde la nave central es doble en dimensiones tanto en altura como en anchura con respecto a las naves laterales. Esta nave central está separada de las naves laterales por cuatro robustos pilares esbeltos de planta cruciforme y arcos de medio punto en la parte más alta, que junto a los pilares, soportan el peso de la bóveda de medio cañón que cubre esta nave principal. Desde el punto de vista longitudinal, y partiendo del extremo de cada uno de los arcos de medio punto laterales, aparecen los arcos fajones, que junto a los arcos de medio punto también actúan soportando prácticamente todo el peso de la bóveda de medio cañón que cubre

${ }^{2}$ A.C.M. (Archivo Catedral de Murcia). Leg. núm. 655. 
esta nave central, marcando estructuralmente cada uno de los tramos que la determinan. En el eje de intersección que aparece entre los arcos de medio punto laterales y los arcos fajones, se originan lunetos, donde quedan situadas unas ventanas rectangulares que hacen penetrar al interior del templo luz natural procedente del exterior (Carrasco, 2004).

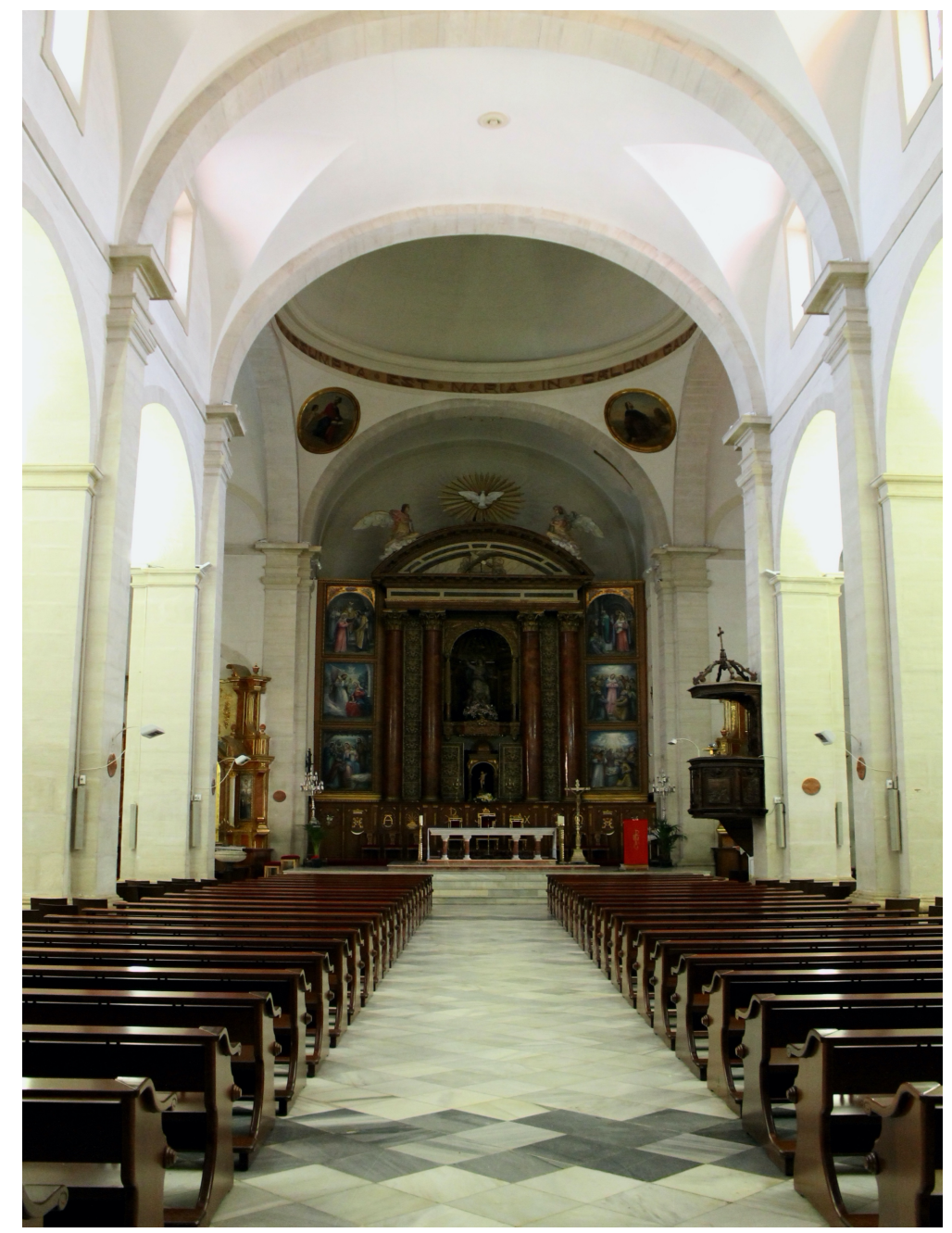

FIGURA 1. TEMPLO DE NUESTRA SEÑORA DE LA ASUNCIÓN DE CIEZA. INTERIOR DE LA NAVE CENTRAL. MANUEL MARÍN RODRÍGUEZ

Al fondo de la imagen anterior se puede contemplar la cabecera del templo, que como se indicó al principio del artículo, fue construida entre los años 1614 y 1615 por los arquitectos Diego de Villabona y Agustín Bernardino (Sánchez, 1985 y 1986; Penalva, 2017), tratándose en este caso de una cabecera de testero plano, cuyo tramo inmediato, en lugar de haberse cubierto por una bóveda de medio cañón como el resto de la nave central del templo, en este caso se optó por aplicar un sistema de cubierta basado en una cúpula sobre pechinas, mientras que las naves laterales del templo quedan cubiertas 
mediante una bóveda de aristas, en cuyos extremos de nuevo se abren grandes arcos de medio punto similares a los construidos en la nave central, que en este caso, actúan soportando la estructura arquitectónica de las naves laterales del templo.

Las obras del templo parroquial de la Asunción de Cieza parece ser que finalizaron hacia 1715 mediante la intervención de Salvador de Mora, ejecutándose el último tramo de la iglesia, que incluiría la fachada principal y el primer cuerpo de la torre (Marín, 2004). No obstante, al cantero Salvador de Mora (Espín, 1986), también se atribuyen las trazas de la capilla que en un primer momento estaría dedicada al patrón de la villa de Cieza, San Bartolomé, actualmente conocida como capilla Santísimo, y las cubiertas de las naves del templo, siendo quizá lo más destacado de su intervención, la ejecución de la portada principal (Carrasco, 2004).

De forma previa a la ejecución de la portada principal de la iglesia de la Asunción de Cieza, en 1713, el cantero Salvador de Mora también llevó a cabo el diseño de la portada principal de la iglesia del convento de la Merced de Murcia, motivo por el cual, se establece que, entre ambas portadas existen características muy comunes desde el punto artístico (Belda y Hernández, 2006), como prueba de ello, es que analizando detenidamente ambas portadas, se podría deducir con facilidad sin consultar la documentación de archivo, que la autoría de ambas portadas podría ser la misma, y de hecho así lo demuestra la propia documentación. No obstante, el cantero Salvador de Mora por encargo del Obispo Belluga, también participó en la ejecución de las obras de las iglesias de San Juan y de Santiago en Lorca (Espín, 1986; Segado, 2012).

La portada principal de iglesia de la Asunción de Cieza, podemos observar que está constituida por dos cuerpos superpuestos en altura bien diferenciados. El primer cuerpo está constituido por la presencia de un arco de medio punto a modo de arco de triunfo romano, similar al de las portadas laterales del templo, por lo que en cierta manera, continúan estando presentes las reminiscencias del estilo renacentista. Este arco de medio punto que determina el vano de acceso al interior del templo, está flanqueado por dos pilastras adosadas en orden gigante con capiteles corintios, una a cada lado del arco central, pilastras que de algún modo parecen estar soportando un entablamento clásico, pero que en realidad no poseen ninguna función estructural, y se convierten en meros elementos decorativos (Marín, 2004; Carrasco, 2004).

El segundo cuerpo actúa como un reflejo de la estructura establecida en el cuerpo inferior, pero en este caso con unas dimensiones bastante más reducidas con respecto a las del primero, estando constituido por otro vano formado por un pequeño arco de medio punto que actúa como hornacina, donde escultóricamente se representa la imagen titular (De la Peña y Hernández, 1994), flanqueado por otras dos pilastras de proporciones bastante menores que las del cuerpo inferior, en este caso soportando sin función arquitectónica alguna, un frontón muy propio del estilo Barroco, y todo a su vez acompañado de los motivos vegetales y roleos comentados.

Se tienen noticias de que, una vez construida la portada principal, el edificio del pósito y diversas casas que se encontraban ubicadas a escasos metros de esta portada principal, ocultaban su monumentalidad, por lo que fue necesario proceder al derribo del edificio del pósito, licencia de obras que parece ser que se consiguió mediante el Real Consejo de las Órdenes el 19 de julio de 1715 (Marín, 2004). Más tarde, hacia 1755 se 
derribó el resto de casas colindantes, todo ello, dando lugar a la apertura de un espacio diáfano que permitió exhibir finalmente la monumentalidad de la Basílica de la Asunción, origen de la actual Plaza Mayor.

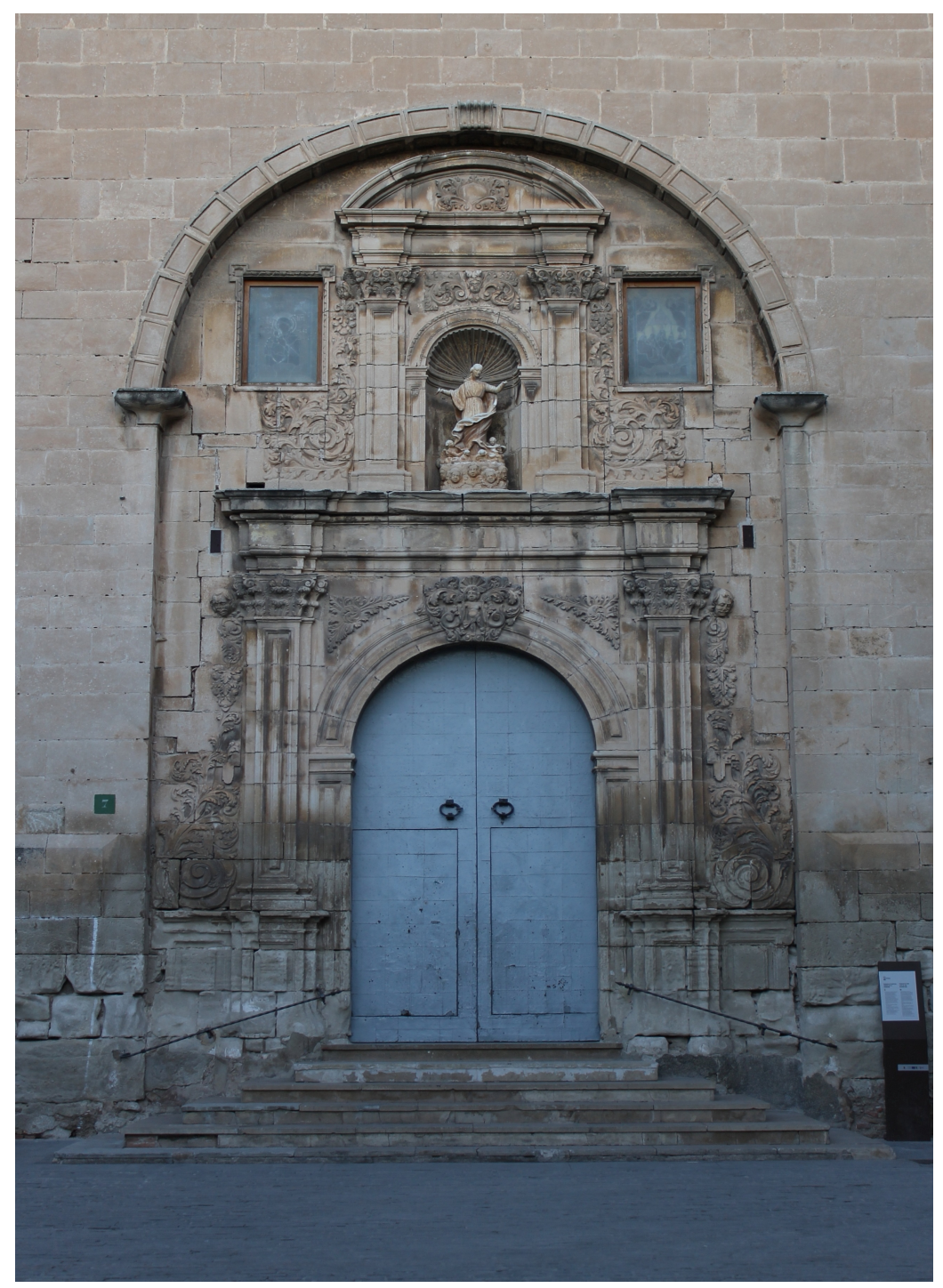

FIGURA 2. TEMPLO DE NUESTRA SEÑORA DE LA ASUNCIÓN DE CIEZA. PORTADA PRINCIPAL. MANUEL MARÍN RODRÍGUEZ

Llegado el siglo XIX, parece ser que la iglesia de la Asunción de Cieza se encontraba bastante deteriorada, por lo que se tuvo que llevar a cabo diversas reformas en el interior del templo. Debido a este motivo, en el año 1829 se iniciaría una campaña de recaudación de fondos para poder financiar los costes de las obras, comenzando finalmente las obras de remodelación de la iglesia hacia 1833, momento en el que también se construyó un cancel para la puerta principal, cuyo diseño fue realizado por el arquitecto 
murciano Carlos Ballester (1769-1839), quien también realizaría otros proyectos de cierta relevancia en la ciudad de Murcia, como fue el caso de la remodelación del Puente de los Peligros (Carrasco, 2000).

Además de las restauraciones y remodelaciones llevadas a cabo en el templo parroquial de Nuestra Señora de la Asunción de Cieza durante el siglo XIX, quizá lo más importante fue la conclusión de su torre-campanario en 1873, obra cuyo encargo recayó en manos del arquitecto murciano José Marín Baldo (1824-1891), construcción que tal y como se desprende del proyecto redactado por el propio arquitecto, quedó incompleta en el siglo XVIII, de modo que su labor se centró en levantar dos cuerpos más por encima del primero, guardando armonía con aquello que ya se encontraba construido desde el siglo pasado (Marín, 2004; Nicolás, 1993).

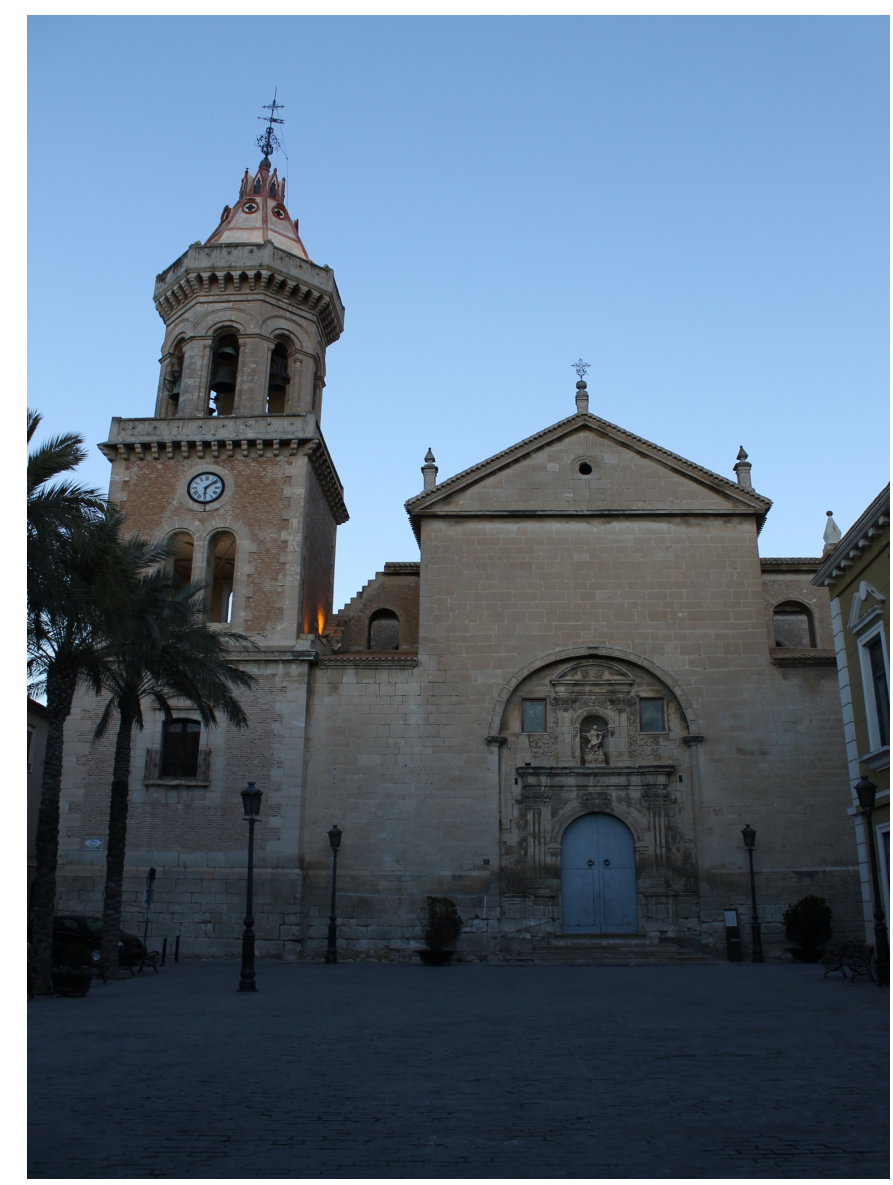

FIGURA 3. TEMPLO DE NUESTRA SEÑORA DE LA ASUNCIÓN DE CIEZA. FACHADA PRINCIPAL Y TORRE. MANUEL MARÍN RODRÍGUEZ

\section{CONSIDERACIONES FINALES}

Como se ha puesto de manifiesto a lo largo del presente artículo, abordar una historia de la construcción del templo parroquial de Nuestra Señora de la Asunción de 
Cieza, es un proceso de investigación cargado de cierta complejidad, puesto que todavía en la actualidad no ha sido posible localizar toda la documentación necesaria que nos permita saber con certeza a quién se deben las trazas originales del templo, aunque de algún modo, existen indicios de aquel que pudo haberlas realizado, tal y como se ha comentado al principio del artículo.

Los estudios locales realizados por historiadores ciezanos como Alfredo Marín Cano y María José Carrasco Campuzano, cuyos datos han sido extraídos en su mayor parte de las actas capitulares del Archivo Municipal de Cieza (A.M.C), y de los protocolos notariales del Archivo Histórico Provincial de Murcia (A.H.P.M), han dado a conocer los nombres de algunos canteros y arquitectos que intervinieron en las obras del templo parroquial de la Asunción entre los siglos XVII y XIX, tales como Diego de Villabona, Agustín Bernardino, Toribio Martínez de la Vega, Salvador de Mora, y José Marín Baldo, que como se ha comentado, culminó las obras de la torre campanario de esta iglesia en 1873, cuyo proyecto original ha quedado plasmado de forma íntegra en el apéndice documental que acompaña al final del artículo.

\section{BIBLIOGRAFÍA}

Amador de los Ríos, R. (1889). España: sus monumentos y artes, su naturaleza e historia. Murcia y Albacete. Barcelona: Daniel Cortezo.

Belda Navarro, C. y Hernández Albaladejo, E. (2006). Arte en la Región de Murcia. De la Reconquista a la Ilustración. Murcia: Editora Regional de Murcia.

Bonet Correa, A. (1991). El urbanismo en España e Hispanoamérica. Madrid: Cátedra.

Calvo García-Tornel, F. (2011). Un ciclo cerrado: el patrimonio nobiliario construido en la ciudad de Murcia. Cuadernos de Turismo, 27, 77-93.

Capdevila Marín, R. M. (1928). Historia de la Muy noble y Muy leal Villa, hoy Excelentísima Ciudad de Cieza del Reino de Murcia desde los más remotos tiempos hasta nuestros días ilustrada con profusión de fotograbados. Tomo II. Murcia: Tipografía del Periódico La Verdad. Carrasco Campuzano, M. J. (2000). Arte en Cieza. En Historia de Cieza. Vol. IV. Murcia: Ayuntamiento de Cieza, 278-289.

Carrasco Campuzano, M. J. (2004). Esplendor Artístico: Renacimiento y Barroco en Cieza. En Historia de Cieza. Vol. III. Murcia: Ayuntamiento de Cieza, 347-380.

Carrasco Campuzano, M. J. (2005). Arte en Cieza: Siglo XX. En Historia de Cieza. Vol. VI. Murcia: Ayuntamiento de Cieza, 263-284.

De la Peña Velasco, C. (1992). La ciudad de Murcia y la política del Concejo en el Barroco. Verdolay, 4, 211-224.

De la Peña Velasco, C. (2001). El Puente Viejo de Murcia. Murcia: Universidad de Murcia.

De la Peña Velasco, C. y Hernández Albaladejo, E. (1994). De la fachada al retablo. Un recorrido por los templos murcianos del siglo XVIII. Imafronte, 10, 69-94.

De la Rosa González, M. (1992). El Monasterio de la Inmaculada Concepción de Cieza. Cieza: Monasterio de la Inmaculada Concepción.

Espín Rael, J. (1986). Artistas y artífices levantinos. Murcia: Real Academia Alfonso X el Sabio. González Simancas, M. (1997). Catálogo Monumental de España; Provincia de Murcia. Tomo II. Murcia: Colegio Oficial de Arquitectos.

Gutiérrez-Cortines Corral, C. (1987). Renacimiento y arquitectura religiosa en la antigua Diócesis de Cartagena. Murcia: Colegio de Aparejadores y Arquitectos Técnicos.

Gutiérrez-Cortines Corral, C. (1990). Murcia: un paradigma urbano del Barroco. En Murcia Barroca. Murcia: Ayuntamiento de Murcia, 50-55.

Gutiérrez-Cortines Corral, C. y Hernández Albaladejo, E. (1983). El crecimiento y la 
modernización de las ciudades en el siglo XVIII. En Francisco Salzillo y el Reino de Murcia en el siglo XVIII. Murcia: Consejería de Cultura y Educación, 68-76.

Hernández Albaladejo, E. (1976). El Puente Viejo de Murcia. Anales de la Universidad de Murcia. Filosofía y Letras, 34, 111-119.

Hernández Albaladejo, E. (1990). La Fachada de la Catedral de Murcia. Murcia: Asamblea Regional.

Hernández Albaladejo, E. (2006). Belluga y el mecenazgo eclesiástico. En Luis Belluga y Moncada: La Dignidad de la Púrpura. Murcia: Fundación CajaMurcia, 69-85.

Hernández Albaladejo, E. y Segado Bravo, P. (1980). Arquitectura y Contrarreforma. En Historia de la Región Murciana. Tomo VI. Murcia: Mediterráneo, 262-317

Hernández Albaladejo, E. y Segado Bravo, P. (1984). El Barroco en la Ciudad y en la Arquitectura. En Historia de la Región Murciana. Vol. VII. Murcia: Mediterráneo, 317-393.

Hernández Vicente, A. (2016). Patrimonio en el recuerdo: la imagen de la nobleza en el paisaje urbano de la ciudad de Murcia. Murcia: Universidad de Murcia.

Marín Cano, A. (2004). San Bartolomé Patrón de Cieza, (Siglos XVI-XXI). Aproximación a la Historia de Cieza a través de sus Ferias y Fiestas. Cieza: Ayuntamiento de Cieza.

Marín Cano, A. (2008). Muerte, Beneficencia, Religiosidad y Cofradías. La Cofradía de Ánimas de Cieza (1574-1997). Cieza: Cofradías de Ánimas.

Nicolás Gómez, D. (1993). Arquitectura y arquitectos del Siglo XIX en Murcia. Murcia: Colegio Oficial de Arquitectos de Murcia.

Penalva Martínez, J. M. La obra del arquitecto Agustín Bernardino en las diócesis de Orihuela y Murcia. Cuadernos de Historia y Patrimonio Cultural del Bajo Segura, 6, 9-39.

Rivas Carmona, J. (2007-2008). Las iglesias barrocas de la ciudad de Murcia: consideraciones sobre su significación y su arquitectura. Imafronte, 19-20, 395-410.

Rodríguez Gutiérrez de Ceballos, A. (2002). La arquitectura de los Jesuitas. Madrid: Edilupa.

Sánchez Portas, J. (1985). El Colegio de Santo Domingo de Orihuela. I. Trazas, Portada, y Claustro de la Universidad. Archivo de Arte Valenciano, 66, 47-52.

Sánchez Portas, J. (1986). Agustín Bernardino, arquitecto francés en el Obispado de Orihuela". En Archivo de Arte Valenciano, 67, 23-26.

Sánchez-Rojas Fenoll, M. C. (1987). Noticias sobre artistas murcianos del siglo XVIII (Años de 1700 a 1730). Murgetana, 71, 91-125

Segado Bravo, P. (2007). La Colegiata de San Patricio de Lorca: Arquitectura y Arte. Murcia: Universidad de Murcia.

Segado Bravo, P. (2012). Lorca Barroca: Arquitectura y Arte. Murcia: Universidad de Murcia. Vera Botí, A. (1990). Arquitectura de los siglos XVII y XVIII en Murcia. En Murcia Barroca. Murcia: Ayuntamiento de Murcia, 30-48.

\section{APÉNDICE DOCUMENTAL}

A.M.M. (Archivo Municipal de Murcia). Sig. 7-H-102.

Proyecto de una Torre para la Iglesia Parroquial de la Villa de Cieza. Memoria Facultativa Redactada por D. José Marín Baldo en 1873:

Encargado por el municipio de la villa de Cieza de la formación de un proyecto para la terminación de la torre de aquella iglesia parroquial, que fuese lo más económico posible y sirviera á la vez que para completar las obras del Templo con esta parte necesaria á sus construcciones, para colocar en ella el reloj de la villa, tuve el honor de presentar mis trabajos á dicha corporación que asociada de otros vecinos mayores contribuyentes, debía recibir mi proyecto y resolver acerca de su ejecución. La extraordinaria benevolencia de los Señores que componían la reunión, llegó al extremo de que se acordase la impresión de este humilde trabajo, 
que por esta razón, y no porque su autor lo crea digno de la publicidad, se imprime con el objeto de que sea conocido por todos los que se interesan en la obra de esta torre. Al consignar este hecho, no puedo prescindir de hacer el merecido elogio de todas las personas que componían la reunión, representando los intereses, las aspiraciones y deseos de la población, sin distinción de clases ni de colores políticos. Todos por unanimidad recibieron con entusiasmo el proyecto, ofreciendo su más decidido apoyo al pensamiento y reconociendo la necesidad de llevarle pronto á cabo, considerando la obra ya como un monumento artístico de embellecimiento público, ya también como una parte necesaria á la Iglesia. Los tiempos que atravesamos, no siendo los mejores para el amor y el respeto debido á los monumentos artísticos; cuando desgraciadamente más se derriban Iglesias consideradas como estorbo de calles y plazas públicas, que no se piensa en edificarlas de nuevo, es muy de bendecir y admirar una villa como la de Cieza, donde se encuentra este tan nombre y generoso sentimiento público, y esta elevación de ideas que hace tiempo escondieron, dejando triunfar desgraciadamente al miserable genio de la vulgaridad, que por todas partes grita diciendo; ;abajo la religión; abajo los monumentos del arte; abajo el patriotismo y caigan y desaparezcan todas las tradiciones, y todos los vínculos sociales y todo quede enrasado y destruido para que se nivelen, asi como las aguas de un estanque, todos los hombres y los pueblos, sin que nada sobresalga ni se levante más que el resto, asumido en la ignorancia de la barbarie! Cuando así se pregona por todas partes la llamada doctrina nueva; doctrina regeneradora; justo, muy justo me parece bendecir y admirar á un pueblo que lejos de afiliarse en banderas tan sangrientas, piensa en levantar una Torre en su Iglesia parroquial, coronando su frente con la cruz de la Redención, símbolo de la fe y origen de la verdadera libertad y de la verdadera civilización cristiana.

La Torre de la Iglesia parroquial de la villa de Cieza se halla construida sobre una planta cuadrada, elevándose hasta la primera cornisa, 11,10 metros sus muros de sillería en el zócalo general y ángulos ó esquinas, con el centro de ladrillo al descubierto, tienen de espesor 1,80 metros en la parte inferior ó sea en su zócalo o basamento general de sillería, que mide tres metros de altura; y 1,60 en el resto de su elevación. El vano interior comprendido por estos muros, es un prisma cuadrangular concéntrico al de los paramentos exteriores de los mismos siendo el lado de su base de 4,85 metros. Esta Torre, quedó sin terminar y cubierta provisionalmente con un tejado informe que vierte aguas á uno de sus costados, desde fines del siglo XVII ó principio del XVIII, que según el carácter de su arquitectura debe ser la época de su construcción.

Es indudable que el primitivo proyecto de la Torre que nos ocupa, debía ser de una altura considerable, como se deduce fácilmente de tales dimensiones y tales espesores de muros en su basamento general, así como también, de las elevaciones que caracterizan toda la arquitectura interior y exterior del templo, en cuyo ángulo N. E se halla comenzada.

Habiendo de armonizar mi proyecto con lo existente debía comenzar por levantar los planos de toda la Iglesia y basamento general de la Torre construida hasta su primera cornisa, y de este estudio resultó que no podía prescindir de elevar las alturas de las nuevas construcciones, de modo que no hubiese notoria contradicción entre estas y la planta del primer cuerpo, que según queda manifestado es un prisma cuadrangular de las dimensiones antedichas. La Iglesia que consideramos pertenece al último periodo del renacimiento, y aunque sencilla y sin el recargo de los adornos y decoración de este género de arquitectura es de proporciones muy esbeltas y de grandioso aspecto. Pilares y arcos de sillería, constituyen sus tres naves, y muros de buena mampostería mixta, reforzados de contrafuertes ó estribos de sillería bien labrada, le dan por lo exterior el aspecto de un templo cristiano anterior á los tiempos en que estos edificios vinieron á construirse con la plantilla sacada del Vignola, empleando las terrajas y el yeso para la formación de sus cornisas y capiteles, tomados de los monumentos de la decadencia de Roma.

La Iglesia que consideramos, sin no un modelo, es un buen ejemplar del arte cristiano en sus últimos tiempos. Algunas obras posteriores á la primitiva construcción, tales como la capilla 
de la comunión, en el crucero, y el centro de la portada principal, son de mal gusto; pero estas obras de destruyen el efecto del conjunto interior ni exteriormente.

De lo dicho resulta que mi proyecto, viene subordinado á guardar armonía con la existente cuando ninguna semejanza tienen los tiempos, ni los recursos de aquellos en que las obras fueron comenzadas, con estos en que nos encontramos, y en los que se pretende concluirlas.

Efectivamente: la Torre que nos ocupa, tiene una base que sin duda se construyó para levantarla á 70 ú 80 metros de altura, lo cual no era demasiado grande empresa cuando la Iglesia contaba con los caudales y rentas de los diezmos; cuando la fe y la piedad de los fieles venían á depositar entre las manos del párroco sus generosas dádivas, para conseguir el que las obras de los templos fueses lo más grandioso y lo más digno de su elevado objeto.

Vivimos en pleno siglo XIX y no son ciertamente nuestros días, aquellos en que los Obispos y los Reyes y los grandes, se disputaban la honra de ir tirando del carro en que se conducía la primera piedra para los cimientos de una Catedral. Hoy sin que la fe se haya perdido en España, es verdaderamente un fenómeno raro para el Arquitecto el encontrar quien lo encargue de semejante proyecto. El espíritu moderno parece más inclinado á el utilitarismo; al empleo de capitales que produzcan un tanto por ciento y que ofrezcan negocio ventajoso, que no á su amortización en las edificaciones de templos, de torres ó de monumentos artísticos. La bolsa y los palacios de las exposiciones de la industria, son hoy las grandes basílicas donde se rinde culto á el dios de las necesidades materiales, de la comodidad, del lujo y de la molicie que vienen corroyendo á nuestra generación. En su ciega vanidad hija de la ignorancia, los hombres que se dicen más adelantados en las ideas de saber y de gobierno, han pretendido establecer el absurdo principio de que la Religión pasó de moda. Triste y desgraciado error que no merece ser combatido ni escuchado siquiera por la razón y el entendimiento humano. Y cuando así son los tiempos y así son las doctrinas y la filosofía con que se pretende regirnos; cuando los intereses materiales todo lo absorben, y las necesidades morales no son, no se quiere que sean, necesidades del hombre; queriendo por lo tanto convertirse en bruto, y descender del alto puesto en que Dios le colocará desde su origen: cuando se niega en pleno parlamento hasta la existencia del mismo Dios y la pureza virginal de María, si bien ningún eco pudieron encontrar éstas blasfemias en la nación que vive al amparo de esa tan torpemente injuriada Virgen Purísima, honor y gloria merece un pueblo como la villa de Cieza, que despreciando tales filósofos y sus doctrinas, siente en su corazón arder la flama del entusiasmo y de la fe: siente necesidades morales que satisfacer y comprende las palabras de Jesús en el desierto. «No solo de pan vive el hombre». Afortunadamente no hemos llegado todavía á el extremo de la degradación, por más que la moderna filosofía se esfuerza en arrastrar á la humanidad por semejantes caminos, á una perdición y á una barbarie sin ejemplo.

¡Dichosos los hombres y los pueblos que experimentan necesidades morales y que las anteponen y consideran preferentes á las materiales de su vida!...Hermoso campo de raciocinio y de discurso aparece á la vista de tales consideraciones. Yo no soy competente para hacer aquí las reflexiones morales y políticas que pudieran hacerse, deduciendo las importantes consecuencias que de estos principios pudieran obtenerse por más acreditados y dignos pensadores. Así pues, y viniendo á nuestro asunto, ó sea á tratar del proyecto que nos ocupa en cuanto me sea permitido dentro de mis escasos recursos y conocimientos, yo dejo á cada cual que medita á su modo sobre el principio que me ha llevado involuntariamente á escribir esta digresión del asunto principal en que debo ocuparme como Arquitecto encargado del proyecto mencionado.

El principio de economía que se me había recomendado observar en los gastos del presupuesto para llevar á cabo estas obras, que habían de ser costeadas por los escasos recursos disponibles al efecto, era lo que más me preocupaba antes de tomar el lapicero y el compas, y así pues empecé por estudiar mi programa basado en este principio, que desgraciadamente preside 
hoy á todo proyecto de arquitectura, privando muchas veces al artista de poder crear y desarrollar su pensamiento con toda libertad, como sucedía en otros tiempos en los cuales no se presupuestaba el coste de las obras ni entraba este documento, hoy tan necesario, entre los que constituían los trabajos del Arquitecto. De mi estudio resultó, que no podía pensar en un proyecto donde el escultor ni el tallista hubieran de emplear sus cinceles para la ejecución de las obras. Y cuando el arte monumental ha de realizarse sin estos auxilios, que le son tan indispensables, desde luego se crece la dificultad del Arquitecto, si bien no es imposible hacer con la mayor sencillez de líneas rectas y de superficies planas un verdadero monumento arquitectónico. En el caso presente debía renunciar á toda decoración costosa y así lo he practicado. Mi proyecto no ha de menester para su realización de otros obreros que el albañil y el cantero del país.

No podía sin embargo de lo dicho, exagerar la observancia de la economía hasta un extremo vicioso copiando una de tantas torres como vemos levantadas en el siglo presente, y muy particularmente en nuestra provincia, que no son otra cosa que cuatro paredes de ladrillo ó de mampostería enlucidas de yeso y pintadas de almagra o creo, ó de azul y de blanco, las cuales elevándose un poco más que las casas que las rodean tienen por remate una cruz y una veleta de hierro. Estas torres, cuyo modelo es por demás conocido constrúyense baratas, y sirven para colgar las campanas de la Iglesia en sus cuatro ventanas ó balcones durante algunos años; pero ninguno que se estime artista, ó que se halla afiliado en tan nobles banderas, puede aceptar ni menos suscribir un proyecto de esta naturaleza ¿No fuera mejor haber construido un campanario de ermita que en solo un murete con dos o tres vanos llevase suspendidas las dos ó tres campanas, que incurrir en la debilidad de haber aceptado tales proyectos de torre? La torre no solo es por su naturaleza un monumento artístico que debe como tal tener la pretensión de pasar á la posteridad atravesando siglos de existencia, sino que es además el centinela constante de la Iglesia, que elevando la cruz á la mayor altura, sostiene las campanas de bronce cuyos timbres argentinos, llaman á la oración á los fieles, anunciando con sus lenguas de metal la venida al mundo de los que nacen, y la partida para la eternidad de los que se mueren. Estas consideraciones no me permitían aceptar una construcción ni unos tales modelos, y habría renunciado á mi honroso encargo, antes que suscribir semejante proyecto, haciendo responsable en lo futuro á la administración que realizara una obra tan desgraciada y que diera idea tan triste de nuestros días.

Difícil es siempre, muy difícil todo proyecto de arquitectura donde el arte deba lucir las galas de la belleza, y donde la construcción cediendo á la composición y la forma el lugar preferente, venga solo á servir como ciencia, las exigencias y las necesidades del arte, pero dificultad se crece hasta lo imposible, cuando el problema hallándose planteado por una generación más rica que se proponía resolverlo con todos los recursos de su tiempo, lo debe concluir de otra generación más pobre y escasa de medios para llevarle á cabo. Estas dificultades no existen para los que se dan por satisfechos con torres que no nombro y que todos conocemos en nuestra capital, construidas recientemente por algún albañil ignorante, y algún párroco más celoso de su Iglesia que no inteligente é instruido como debiera, y falto de toda noción y conocimiento de las artes. El modo más sencillo, de evitar todas estas dificultades é inconvenientes, con otras que no se mencionan y que la administración municipal encuentra para la realización de su proyecto, salidas de donde menos fuera de esperar ningún obstáculo á este tan noble pensamiento, sería el de abandonarlo diciendo: «No hagamos la torre, que no nos hace falta para vivir, y sin ella hemos pasado hasta hoy sin ella pasaremos de igual modo mañana».

Con estas y otras semejantes fáciles palabras que nada cuestan y que dicta el genio del egoísmo, y la sobra de amor propio, la falta de fe y la torpe indiferencia, el problema queda resuelto sin hacer ningún sacrificio; pero no es esto, no, lo que se desea por los hijos de la villa de Cieza que con tanto entusiasmo como poca fortuna acaban de levantar una ermita en las inmediaciones de su vecindario, gastando en ella cuantiosos recursos obtenidos de limosnas y consignaciones hechas en su presupuesto municipal. Cieza quiere levantar la obra de su Torre y es necesario estudiar un proyecto que satisfaga á las condiciones siguientes: 
$1^{a}$. Economía de gasto.

$2^{\text {a }}$. Belleza y armonía con lo existente y carácter propio de la arquitectura religiosa.

3. Solidez necesaria á un monumento público.

Lo primero, ó sea la economía, no puede nunca considerarse en absoluto: La significación es siempre relativa, y se ha procurado satisfacerlo con toda la prudencia necesaria. El presupuesto de la construcción del proyecto que se acompaña asciende á la escasa cantidad de 16.985,99 pesetas y esta suma que parecerá mucho ó poco, según sea el criterio y las ideas de quien la considere, á mi me ha parecido lo más reducida y más económica posible.

Lo segundo, exige en primer lugar, gusto é inspiración artística, cuyas dotes no se encuentran por desgracia muy sobradas en el autor de este proyecto. Así que solo diré respecto de este punto que he procurado hacer lo que me ha sido posible para llevar sus condiciones dentro de mis escasas facultades y conocimientos del arte que poseo. La condición tercera, que exige solidez propia de un monumento público, es la que no puede conseguirse de otro modo que empleando los buenos materiales propios de una construcción espléndida, y abandonando el sistema ordinario de las edificaciones del país, ó sean las mamposterías y muros de ladrillo con mortero de yeso, enlucidas ó revocadas con el mismo. Semejantes obras son perecederas y deleznables como acredita la práctica diaria en todos los edificios construidos de este modo. Así pues, hemos adoptado la sillería de las canteras de Ascoy que reúne todas las condiciones de bondad propias de este material, asentada con mortero fino de cal para todas las esquinas, aristas y cornisas del segundo cuerpo, conservando de este modo la armonía necesaria con la obra del primero que se nos da construido. Lo demás de los muros de este segundo cuerpo es de ladrillo sentado con igual clase de mortero, empleando el fino de colores para los paramentos exteriores.

Como el vano interior comprendido entre los cuatro muros de la base, no podemos reducirlo y debe conservarse de 4,85 metros de lado para no venir á cargar en el aire las obras nuevas, el espesor de muros de este segundo cuerpo, que por el cálculo de resistencias se habría podido reducir á 0,85 metros, los hemos debido de conservar de 1,10 metros, por no estrechar exageradamente el ancho exterior de esta parte de la torre, lo cual habría sido de mal efecto comparado y relacionado con la base que tan robusta y ancha fue construida.

Elévese este segundo cuerpo sobre la altura que tiene el primero á 9,80 metros más, resultado que su cornisa se halla 19,90 metros sobre la línea de tierra. Sobre esta cornisa se halla establecido un balcón con antepecho de sillería que recorre todo su contorno general en las cuatro fachadas, elevándose el tercer cuerpo de forma octogonal 9,00 metros sobre las dichas alturas. Este cuerpo tercero, lo forman ocho pilares de sillería labrados y cornados de ocho arcos semicirculares siguiendo en sus archivoltas las molduras de los dichos pilares según el estilo romano bizantino de su arquitectura. Por último se remata esta torre con una cubierta piramidal calada de algunos vanos, y decorada sencillamente con los dibujos obtenidos por las tejas de colores planos y barnizadas que forman sus ocho paramentos ó caras triangulares. La terminación ó cúspide de la pirámide, lleva por adorno una pequeña esfera de donde arranca la veleta y cruz de hierro, la altura total de 41 metros á partir desde el plan terreno ó base inferior de la torre que nos ocupa. Nada diré respecto de las obras interiores que son de escasa importancia y que se hallan como todo lo demás perfecta y claramente descritas en los planos y pliego de condiciones que se acompañan. La solidez ó sea la tercera condición que nos habíamos impuesto, creo que se halla sobradamente satisfecha, tanto más, cuanto que el exceso de espesores de muros y la necesidad de reducir las alturas para no exceder los gastos del presupuesto, han hecho acaso perjuicio á la belleza, á la esbeltez y ligereza que habríamos deseado dar al conjunto de nuestro proyecto, favoreciendo considerablemente la estabilidad de su mole, un tanto pesada, bajo el punto de vista del arte. 
No debo concluir la presente memoria sin hacer constar los nombres de las personas que asistieron á la reunión provocada por el Ayuntamiento para recibir mi proyecto, y que con tanto entusiasmo y decisión le apoyaron, no por su mérito artístico que muy escaso lo tiene, sino por ser el proyecto de una obra deseada, de una obra que puede y debe contribuir al embellecimiento de la villa de Cieza y más que todo á completar las necesidades de su iglesia parroquial. Los Sres. D. Antonio Tellez Marín, Alcalde y presidente de la reunión; D. Antonio Marín y Marín, abogado; D. Isidro Gómez Marzo, magistrado cesante; D. Francisco González Condón, abogado; D. Francisco Martínez, abogado, D. Mariano Marín Blázquez, propietario; D. Pascual Capdevila Marín, Propietario; D. Similiano López del Castillo, sindico del Ayuntamiento y el ilustrado secretario del mismo D. Bartolomé Molina, todos estos señores representando á la villa de Cieza en su deseo y aspiraciones, merecen el reconocimiento del arte y de la religión católica, por haber concebido y apoyado el pensamiento de esta obra en pleno año de 1872.

J. M. B. 